\title{
Silver Nanoparticles: Novel Antimicrobial Agent Synthesized from an Endophytic Fungus Pestalotia sp. Isolated from Leaves of Syzygium cumini (L)
}

Farkanda Raheman, Shivaji Deshmukh, Avinash Ingle, Aniket Gade, Mahendra Rai*

Department of Biotechnology, Sant Gadge Baba Amravati University, Amravati, 444602, Maharashtra, India.

* Corresponding author: mkrai123@rediffmail.com; pmkrai@hotmail.com (Mahendra K. Rai Prof. Dr.)

\begin{abstract}
We report the extracellular synthesis of silver nanoparticles using an endophytic fungus Pestalotia sp. isolated from leaves of Syzygium cumini (L) and their antibacterial activity against human pathogenic bacteria viz. Staphylococcus aureus (ATCC-25923) and Salmonella typhi (ATCC-51812) alone and in combination with commercially available antibiotics. Detection of synthesized silver nanoparticles was carried out using UV-Visible spectrophotometer analysis, which showed a peak at $415 \mathrm{~nm}$ indicating the formation of nanoparticles. Further characterization includes the Fourier Transform Infra-Red spectroscopic analysis for the detection of proteins as capping agents on nanoparticles. Nanoparticle Tracking and analysis (LM 20) and TEM analysis confirmed the formation of spherical and polydispersed nanoparticles in the range of 10-40 nm having average size of 12.40 $\mathrm{nm}$.

Biologically synthesized silver nanoparticles showed significant antibacterial activity but their efficacy was increased in combination of antibiotics like gentamycin and sulphamethizole. Silver nanoparticles in combination with gentamycin showed maximum activity (30 mm) against $S$. aureus followed by sulphamethizole $(25 \mathrm{~mm})$. Similar results were reported in case of $S$. typhi where silver nanoparticles in combination with gentamycin $(28$ $\mathrm{mm}$ ) showed more activity than combination of silver nanoparticles and sulphamethizole $(24 \mathrm{~mm})$.

Biosynthetic approach using an endophytic fungus is a novel way towards the development of safe, economically viable and green method for the synthesis of silver nanoparticles and thus synthesized silver nanoparticles can be used in antibacterial formulations.
\end{abstract}

Keywords: Endophyte, Silver Nanoparticles, Antibiotics, Economically viable, Synergestic effect

Citation: F. Raheman, et al. Silver nanoparticles: Novel antimicrobial agent synthesized from an endophytic fungus Pestalotia sp. isolated from leaves of Syzygium cumini (L). Nano Biomed. Eng. 2011,3(3), 174-178. DOI: 10.5101/nbe.v3i3.p174-178.

\section{Introduction}

Metal nanoparticles have promising applications in the fields of medicine, electronics, agriculture, etc. In the present scenario pharmaceutical and biomedical sector are facing the challenge of continuous increase in the emerging pathogens, with their antibiotic resistance profiles, with fear about the emergence and re-emergence of multi-drug resistant pathogens and parasites [1]. Therefore, in this modern era the priority areas of research are concerning the development or modification in antimicrobial compounds in order to improve bactericidal potential.

Nanotechnology is the engineering and technological applications of the nanomaterials and nanoparticles of size ranging from $(1-100 \mathrm{~nm})[2,3]$. Nanotechnology provide platform to modify and develop the important properties of metal in the form of nanoparticles having promising applications in diagnostics, biomarkers, cell labeling, contrast agents for biological imaging, antimicrobial agents, drug delivery systems and nanodrugs for treatment of various diseases $[4,5]$.

The researchers are moving towards nanoparticles especially silver nanoparticles to solve the problem of emerging pathogens including multi-drug resistant bacteria $[6,7]$. Silver nanoparticles are more effective because of the high surface area to volume ratio so that a large proportion of silver nanoparticles is in direct contact with their environment [8].

Many fungi like Fusarium acuminatum [8], F. solani [9] Aspergillus niger [10] Phoma glomerata 
[3] Alternaria alternata [11], F. culmorum [12] etc. have been successfully used for the synthesis of silver nanoparticles. These studies confirmed that among the different biological agents, fungi are more efficient candidates for fabrication of metal nanoparticles both intra- and extracellulary [13]. Extracellular biosynthesis of silver nanoparticles using fungi has advantages like more simple and eco-friendly approach as compared to chemical and physical methods [8], The antimicrobial potential of silver nanoparticles have been examined and found to be effective against many pathogens [14, 15] Ingle et al [8]. demonstrated antibacterial activity of silver nanoparticles synthesized from $F$. acuminatum against human pathogenic bacteria like S. typhi, E. coli, S. epidermidis and multi-drug resistant $S$. aureus, Similarly, Gade and colleagues [10], reported antibacterial activity of silver nanoparticles against Gram-positive $(S$. aureus) and Gram-negative (E. coli) bacteria. Besides antimicrobial agents, silver nanoparticles are used in bio-labeling biosensors and filters [17], nano dressings and textile fabrics beneficial for the burnt patients,[18] for surgical masks, [19] in tissue conditioner [20], etc. Thus, silver nanoparticles are the ideal candidate for the development of novel antimicrobial product and these are said to be antimicrobials of new generations [21].

In the present study, we have used an endophytic Pestalotia sp. isolated from healthy leaves of Syzygium cumini (L.) for the extracellular synthesis of silver nanoparticles. We also evaluated their antibacterial activity. The main reason behind the use of endophytic fungus was that being an endophyte it is non pathogenic in nature and therefore, easy to handle and culture.

\section{Materials and methods}

\subsection{Isolation and identification of endophytic Pestalotia sp.}

Healthy leaves of Syzygium cumini (L) were collected from the campus of S. G. B. Amravati University, Amravati. Leaves were thoroughly washed in sterile distilled water and cut into small pieces. These pieces were surface sterilized using $1 \% \mathrm{NaOCl}$ for $30 \mathrm{sec}$, washed with sterilized distilled water (2 times) and dried on paper towel. These pieces were then inoculated on petri-plates containing sterilized potato dextrose agar (PDA) and incubated at $28 \pm 2^{\circ} \mathrm{C}$ for $8-15$ days. The fungus Pestalotia sp. have been identified on the basis of morphological and cultural characteristics like color of colony, growth rate, type of mycelium etc.

\subsection{Extracellular synthesis of silver nanoparticles}

For the synthesis of silver nanoparticles, the endophytic fungus Pestalotia sp. was grown in $250 \mathrm{ml}$ flask containing $100 \mathrm{ml}$ potato dextrose broth (PDB) at 28 ${ }^{0} \mathrm{C}$ for 72 hours and then harvested biomass was filtered through Whatman filter paper No.1. The fungal mat was then washed with distilled water to remove media component and suspended in $100 \mathrm{ml}$ distilled water for 48 hours. After 48 hours of incubation, the cell filtrate was separated by filtration. Fungal cell filtrate was collected and challenged with the $\mathrm{AgNO}_{3}$ salt (final conc. $1 \mathrm{mM}$ ).

\subsection{Detection of silver nanoparticles by UV- Visible spectrophotometer}

After 2 hours of incubation, the reaction mixture was subjected to UV-Visible spectrophotometer analysis (Shimadzu UV-1700, Japan). The spectrum was scanned at the resolution of $1 \mathrm{~nm}$ from $200-800 \mathrm{~nm}$ for each sample.

\subsection{Characterization of silver nanoparticles}

\subsubsection{Fourier Transform Infrared} Spectroscopic (FTIR) Analysis: After complete reduction of aqueous silver ions in to silver nanoparticle, the collidal solution with acetone in (1:5) was subjected to centrifugation at $4000 \mathrm{rpm}$ for $15 \mathrm{~min}$ after continuous shaking (2 times). Later, supernatant was discarded and 1-2 $\mathrm{ml}$ acetone was added into the pellet. After shaking thoroughly, it was poured into the petri plate. Acetone was then allowed to evaporate in order to obtain the powder of nanoparticles. Characterization of AgNPs was carried out by FTIR (Perkin- Elmer FTIR-1600, USA) in the range $500-4000 \mathrm{~cm}^{-1}$ at a resolution of $4 \mathrm{~cm}^{-1}$. FTIR reveals the biomolecules responsible for the reduction of silver ions and stabilization of silver nanoparticles in the solution.

\subsubsection{Nanoparticle Tracking and Analysis} System (NTA) (LM 20): The size of synthesized nanoparticles was measured by Nanosight (LM-20, UK). The sample was diluted with the nuclease free water and $0.5 \mathrm{ml}$ of diluted sample was injected onto the sample chamber and observed through LM 20 to measure the size of the nanoparticles.

2.4.3 TEM analysis: The characterization of silver nanoparticles was also done by TEM (Philips, CM 12), on conventional carbon coated copper grids (400 meshes, Plano Gmbh, Germany). A $5 \mu$ of sample was taken for the characterization and three image of each sample were taken for the clarification of the composition

\subsection{Evaluation of antibacterial activity of silver nanoparticles}

Antibacterial activity of silver nanoparticles alone and in combination with antibiotics was evaluated using Kierby-Bauer disc diffusion method, against Staphylococcus aureus (ATCC-25923) and Salmonella typhi (ATCC-51812) procured from American Type Culture Collection Center, USA. The Mueller- Hinton agar medium was prepared and sterilized at $121{ }^{\circ} \mathrm{C}$ and 15 lbs pressure for $15 \mathrm{~min}$, poured and allowed to solidify in the sterilized petri-plates. The overnight grown bacterial cultures of both bacteria having approx. $10^{5} \mathrm{CFU} \mathrm{ml}^{-1}$ were inoculated; four different types of disks control, silver nanoparticle, standard antibiotic Gentamycin and 


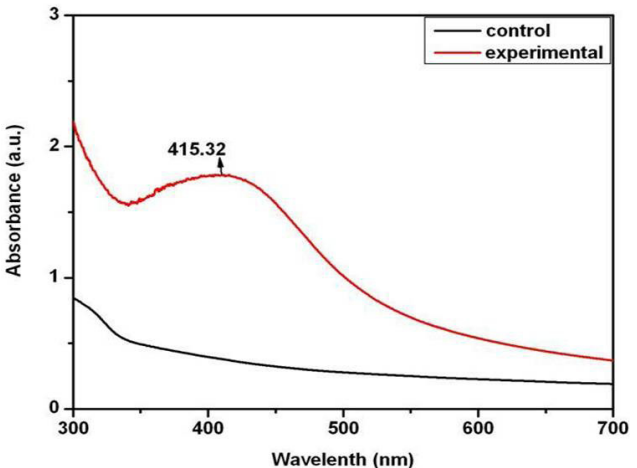

Fig. 2 UV-Visible spectra of fungal cell filtrate (showing no peak) and silver nanoparticles showing peak at $415 \mathrm{~nm}$.

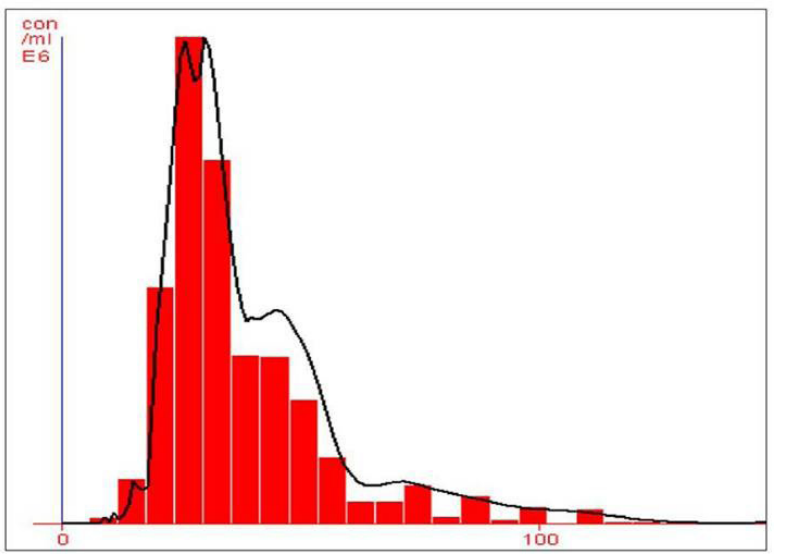

Fig. 4 NTA (Nanosight-LM 20) nanoparticle size distribution histogram showing the average size of $26 \mathrm{~nm}$.

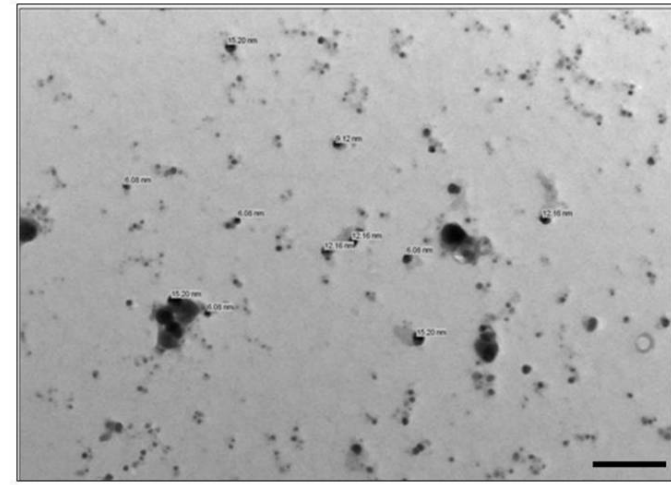

Fig. 6 TEM micrograph showing synthesis of polydispersed and spherical silver nanoparticle having average size of $12.40 \mathrm{~nm}$ (scale bar $100 \mathrm{~nm})$. distribution

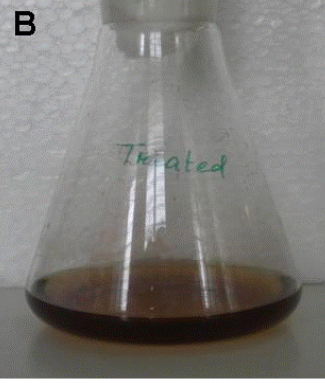
Fungal cell filtrate after treatment of $\mathrm{AgNO}_{3}$ (experimental).

for silver nanoparticles.
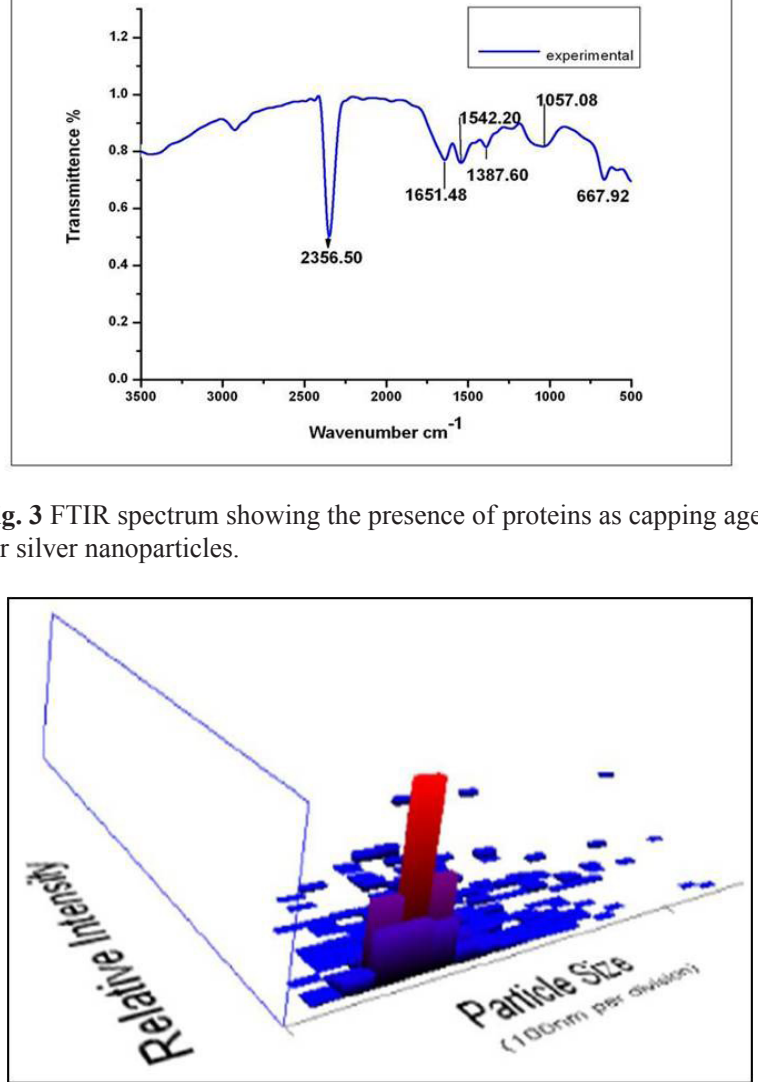

Table 1. Comparison of antibacterial activity of silver nanoparticles, synthesized from endophytic fungus Pestalotia sp, alone and in combination with antibiotics against test bacteria.

\begin{tabular}{|c|c|c|c|c|c|}
\hline \multirow{2}{*}{ Antibiotics } & $\begin{array}{c}\text { Test } \\
\text { Bacteria }\end{array}$ & $\begin{array}{c}\text { Zone of Inhibitions } \\
\text { (Antibiotic) in mm (A)* }\end{array}$ & $\begin{array}{c}\text { Zone of Inhibition } \\
\text { (Nanoparticles) in mm }\end{array}$ & $\begin{array}{c}\text { Zone of Inhibitions } \\
\text { (Antibiotic }+ \text { Silver } \\
\text { nanoparticle) in mm }(\mathrm{B}) *\end{array}$ & $\begin{array}{c}\text { Increase in Fold Area } \\
\text { of Zone of Inhibition in } \\
\mathrm{mm}^{*}+\left(\mathrm{B}^{2}-\mathrm{A}^{2}\right) / \mathrm{A}^{2}\end{array}$ \\
\hline \multirow{2}{*}{ Sulphamethin } & S. aureus & 27 & 12 & 30 & 0.23 \\
\cline { 2 - 7 } & S. typhi & 26 & 10 & 28 & 0.15 \\
\cline { 2 - 7 } & S. aureus & 23 & 12 & 25 & 0.18 \\
\hline
\end{tabular}

* Mean surface area of the inhibition zone was calculated for each from the mean diameter. +Increase in fold area was calculated as $\left(\mathrm{B}^{2}-\mathrm{A}^{2}\right) / \mathrm{A}^{2}$, where 'A' and 'B' are the inhibition zones for Antibiotic and Antibiotic + silver nanoparticles respectively. 
sulphamethizole purchased from Hi-Media (Mumbai, India) and the combination of silver nanoparticles with standard antibiotic mentioned above were placed on the surface of the agar. Plates were incubated for 24 hours at $37^{\circ} \mathrm{C}$, Zone of inhibition was measured. The assay was performed in triplicates.

\subsection{Assessment of increase in fold area}

The increase in fold area was assessed by calculating the mean surface area of the inhibition zone of each antibiotic (gentamycin and sulphmethizole) and antibiotic + silver nanoparticle. The fold increase area of $S$. aureus and $S$. typh $i$ was calculated by the equation $\left(\mathrm{B}^{2}-\mathrm{A}^{2}\right) / \mathrm{A}^{2}$ where ' $A$ ' and ' $B$ ' were zones of inhibition for antibiotic and antibiotic + silver nanoparticles, respectively [3].

\section{Results and Discussion}

The rapid change in color from yellowish to darkbrown was observed in the fungal cell filtrate after addition of the aqueous silver ions $\left(\mathrm{AgNO}_{3}\right)$ due to the reduction of silver ions to silver nanoparticles i.e. $\mathrm{Ag}^{+}$ to $\mathrm{Ag}^{0}$. The appearance of brown color indicates the synthesis of silver nanoparticles (Fig. 1). These findings showed the similarity with the results reported by many researchers in past $[8,22,23]$, who used different fungal system for the synthesis of silver nanoparticles. The formation of silver nanoparticles in fungal cell filtrate was further characterized by using UV-Vis spectrophotometer based on its characteristics surface plasmon resonance[8]. The reaction mixture after treatment with aqueous silver ions and subjected to optical analysis using UV-Vis spectrophotometer showed a sharp peak at $415 \mathrm{~nm}$ which is specific for silver nanoparticles and appeared due to plasmon resonance [24] (Fig. 2).

FTIR spectrum revealed that the silver nanoparticles synthesized from endophytic fungus Pestalotia sp. showed the presence of peak at 1651.4, 1542, 1387 and $1057 \mathrm{~cm}^{-1}$ (Fig. 3). The bands at $1651.4,1542.4$ corresponds to the bonding vibrations of the amide I and amide II bands of proteins while the bands obtained at $1387 \mathrm{~cm}^{-1}$ and 1057 $\mathrm{cm}^{-1}$ are due to presence of $\mathrm{C}-\mathrm{N}$ stretching vibrations of aromatic and aliphatic amines. These results resembles with the findings of Gole and colleague [25] who reported that proteins can bind to nanoparticles either through free amine groups or cystein residues or through the electrostatic attraction of negatively charged carboxylate groups in enzymes present in cell-wall of mycelia. Nonconjugated aliphatic $\mathrm{C}=\mathrm{C}$ and $\mathrm{C}=\mathrm{N}$ have absorption bands at 1690 to $1620 \mathrm{~cm}^{-1}$, with variable intensities. Molecules containing $\mathrm{NO}_{2}$ groups, such as nitro compounds, nitrates, and nitramines, commonly exhibit asymmetric and symmetric stretching vibrations of the $\mathrm{NO}_{2}$ group at 1660 to 1500 and 1390 to $1260 \mathrm{~cm}^{-1}$ region. FTIR spectroscopy has confirmed that amino acid residues and peptides of proteins has the stronger ability to bind with metal, so that the proteins could most possibly form a coat covering the metal nanoparticles i.e. (capping of silver nanoparticles) to prevent agglomeration of the particles and stabilizing in the medium [26].

Nanoparticle tracking and analysis (NTA) was carried using NanoSight LM-20 to measure the dispersion characteristics, i.e. size and distribution. In particular, it is the most recently developed system; NTA was assessed in-depth due to its ability to measure the size of particles individually on a particle-by-particle basis. NTA allows individual nanoparticles in a suspension to be microscopically visualized and their Brownian motion to be separately but simultaneously analyzed, from which the particle size distribution can be obtained. The average size of nanoparticles from the NTA analysis was found to be $26 \mathrm{~nm}$. Fig. 4 and Fig. 5 showed the particle size distribution histogram and 3-D plot of particle size distribution respectively. These results corroborate the results obtained by Montes-Burgos and group [27]. TEM analysis finally confirmed the synthesis of spherical and polydispersive silver nanoparticles in the reaction mixture. The particles are in the range of 10-40 nm with average diameter of $12.40 \mathrm{~nm}$ (Fig. 6).

In vitro antimicrobial activity, of silver nanoparticles produced from endophytic fungus Pestalotia sp. was carried out without antibiotics and in combination with commercially available antibiotics gentamycin and sulphamethizole against $S$. aureus and S. typhi. Silver nanoparticles without antibiotics showed antibacterial activity but the efficiency was found to be increased significantly in combination with antibiotics. Silver nanoparticles in combination with gentamycin showed maximum activity $(30 \mathrm{~mm})$ (increase in fold area-0.23) against $S$. aureus followed by sulphamethizole (25 $\mathrm{mm}$ ) (increase in fold area-0.18). Similar results were reported in case of $S$. typhi where silver nanoparticles in combination with gentamycin $(28 \mathrm{~mm})$ (increase in fold area-0.15) showed more activity than combination of silver nanoparticles and sulphamethizole $(24 \mathrm{~mm})$ (increase in fold area-0.08) (Table 1).

Above results corroborates with the findings reported by Birla et al [3]. who reported that in vitro activity of commercially available antibiotics was significantly increased in the presence of silver nanoparticles produced from Phoma glomerata. Similarly, Gajbhiye et al [11] also demonstrated the increase in the efficacy of silver nanoparticles in presence of standard antibiotics.

\section{Conclusion}

It has been demonstrated that the endophytic fungus Pestalotia sp. is capable of producing silver nanoparticles extracellulary which are quite stable in solution due to capping by the proteins present in the cell filtrate. This is an efficient, eco-friendly and simple process. The silver nanoparticles showed significant antibacterial activity. Their efficacy increased when used in combination with commercially available antibiotics. Therefore, such silver nanoparticles can be used as antimicrobial agent alone or in combination with antibiotics after further trials on experimental animals. 


\section{References}

1. Tenover FC. Mechanisms of antimicrobial resistance in bacteria. Am J. Medicine. 2006; 119:3-10. http://dx.doi.org/10.1016/j.amjmed. 2006.03.011

2. Mihail CR. Nanotechnology: convergence with modern biology and medicine. Curr. Opn. Biotechnol.2003; 14:337-346. doi:10.1016/ S0958-1669(03)00068-5.

3. Birla SS, Tiwari VV, Gade AK, Ingle AP, Yadav AP, Rai MK. Fabrication of silver nanoparticles by Phoma glomerata and its combined effect against Escherichia coli. Pseudomonas aeruginosa and Staphylococcus aureus. Lett. in App. Microbio.2009; 48(2):173179 (2009). doi:10.1111/j.1472-765X.2008.02510.x

4. Le AT, Huy PT, Tam LT, Tam PD, Hieu N, Huy T. Novel silver nanoparticles: synthesis, properties and applications. Int. J. of Nanotechnol. 2011; 8(3):278-290. http://dx.doi.org/10.1504/ IJNT.2011.038205

5. Singh R, Singh NH, Medical Applications of Nanoparticles in Biological Imaging, Cell Labeling, Antimicrobial Agents, and Anticancer. Nanodrugs, J. Biomed. Nanotechnol. 2011; 7(4):489-503. http://dx.doi.org/10.1166/jbn.2011.1324

6. Gemmell CG, Edwards DI, Frainse AP. Guidelines for the prophylaxis and treatment of methicillin-resistant Staphylococcus aureus (MRSA) infections in the UK. J. Antimicrob. Chemother. 2006; 57:589-608. http://dx.doi.org/10.1093/jac/dk1017

7. Chopra I, The increasing use of silver-based products as antimicrobial agents: a useful development or a cause for concern? J. Antimicrob. Chemother. 2007; 59:587-90. http://dx.doi.org/10.1093/jac/dkm203

8. Ingle A, Gade A, Pierrat S, Sonnichsen C, Rai M. Mycosynthesis of silver nanoparticles using the fungus Fusarium acuminatum and its activity against some human pathogenic bacteria. Curr. Nano. 2008; 4:141-44. http://dx.doi.org/10.2174/157341308784340804

9. Ingle I, Gade A, Bawaskar M, Rai M. Fusarium solani: a novel biological agent for the extracellular synthesis of silver nanoparticles. J. Nanopart. Res. 2011; 11:2079-85. http://dx.doi.org/10.1007/ s11051-008-9573-y

10.Gade AK, Bonde P, Ingle AP, Marcato PD, Duran N, Rai MK. Exploitation of Aspergillus niger for synthesis of silver nanoparticles, J. Biobased. Mater. Bioener. 2008; 2:243-247. http://dx.doi. org/10.1166/JPMB.2008.401

11.Gajbhiye M, Kesharwani J, Ingle A, Gade A, Rai M. Fungusmediated synthesis of silver nanoparticles and their activity against pathogenic fungi in combination with fluconazole. Nanomedicine: Nanotech. Bio. and Med. 2009; 5:382-386. http://dx.doi.org/10.1016/ j.nano.2009.06.005

12.Bawaskar M, Gaikwad S, Ingle A, Rathod D, Gade A, Duran N, Marcato PD, Rai M, A New Report on Mycosynthesis of Silver Nanoparticles by Fusarium culmorum, Curr. Nanosci.2010; 6:376380. http://dx.doi.org/10.2174/157341310791658919

13.Gade A, Ingle C, Whiteley, Rai M, Mycogenic metal nanoparticles: progress and applications. Biotechnol. Lett. 2010; 32(5):593-600. http://dx.doi.org/10.1007/s10529-009-0197-9

14. Gade A, Gaikwad S, Tiwari V, Yadav A, Ingle A, Rai M. Biofabrication of Silver Nanoparticles by Opuntia ficusindica: In vitro antibacterial activity and study of the mechanism involved in the synthesis, Curr. Nanosci. 2010;6:370-75. http://dx.doi.org/10.2174/157341310791659026

15. Govindaraju K, Tamilselvan M, Kiruthiga V, Singaravelu G. Biogenic silver nanoparticles by Solanum torvum and their promising antimicrobial activity Antimicrobial activity of silver nanoparticles, Journal of Biopesticides. 2010; 3(1):394-399.

16. Namasivayam SKR, Ganesh S, Avimanyu. Evaluation of antibacterial activity of silver nanoparticles synthesized from Candida glabrata and Fusarium oxysporum. Int. J. Med. Res. 2011;1(3):131136.

17. Cao G, Editor, Nanostructure and Nanomaterials: Synthesis, Properties and applications, Imperial college press, London 2004.

18. Duran N, Marcato PD, De Souza GI, Alves H, Esposito E. Antibacterial effect of silver nanoparticles produced by fungal process on textile fabrics and their effluent treatment. J. Biomed. Nanotech. 2007; 3,203-8. http://dx.doi.org/10.1166/jbn.2007.022

19. Li Y, Leung P, Song QW, Newton E. Antimicrobial effects of surgical masks coated with nanoparticles. J. Hosp. Infect. 2006; 62:58-63. http://dx.doi.org/10.1016/j.jhin.2005.04.015

20. Ki YN. In vitro antimicrobial effect of the tissue conditioner containing silver nanoparticles. J. Adv. Prosthodont. 2011; 3:20-24. http://dx.doi.org/10.4047/jap.2011.3.1.20

21. Rai M, Yadav A, Gade A. Silver nanoparticles as a new generation of antimicrobials. Biotech. Advances. 2009; 27:76-83. http://dx.doi. org/10.1016/j.biotechadv.2008.09.002

22. Gardea-Torresedey JL, Gomez E, Jose-Yacaman M, Parsons JG, Peralta-Videa JR, Tioani $H$. Alfalfa sprouts: A natural source for the synthesis of silver nanoparticles. Langmuir. 2003; 19:1357-61. http://dx.doi.org/10.1021/la020835i

23. Jones SA, Bowler PG, Walker M, Parsons D. Controlling wound bioburden with a novel silver-containing Hydrofiber dressing. Wound Repair Regen. 2004; 12:288-294. http://dx.doi.org/10.1111/ j.1067-1927.2004.012304.x

24. Sastry M, Ahmad A, Khan MI. Kumar R. Biosynthesis of metal nanoparticles using fungi and actinomycete. Curr. Sci. 2003; 85(2):162-170

25. Gole A, Dash C, Ramakrishnan V, Sainker SR, Mandale AB, Rao M. Sastry M. Pepsin-gold colloid conjugates: preparation, characterization and enzymatic activity. Langmuir. 2001; 17(5):1674-79. http://dx.doi.org/10.1021/la001164w

26. Basavaraja S, Balaji SD, Lagashetty A, Rajasab AH. Venkataraman A. Extracellular biosynthesis of silver nanoparticle using the fungus Fusarium semitectum. Mate. Res. Bullatin. 2008; 45(5): 1164-70. (2008). doi:10.1016/j.materresbull.2007.06.020.

27. Montes-Burgos I, Walczyk D, Hole P, Smith J, Lynch I. Dawson K. Characterisation of nanoparticle size and state prior to nanotoxicological studies J. Nanopart. Res. 2010; 12(1):47-53. doi10.1007/ s11051-009-9774-z.

Copyright:(c) 2011 F. Raheman, et al. This is an openaccess article distributed under the terms of the Creative Commons Attribution License, which permits unrestricted use, distribution, and reproduction in any medium, provided the original author and source are credited. 